\title{
Humanitarization Geographic Education in Universities
}

\author{
Gaisin R.I.a \\ Beketova S.V.b \\ Vlasova E.I.c \\ Sharapova G.F.d
}

abcd Kazan Federal University, Institute of Management, Economics and Finance, Kazan, 420008, Russia

\section{Doi:10.5901/mjss.2015.v6n1s3p131}

\section{Abstract}

This article discusses the structure of science. Highlighted border integration and cross-cutting areas. Considered the most important priorities of the Russian geographical education; humanization, aimed at the development of common cultural components in the content of education in the formation of personality; humanization, expressed by an emphasis on personal factors, the social aspects of the development of society; sociologization, object of study is sociosphere - a set of geographic and socio-economic factors, with increased attention to the social aspects of development; greening, reflecting spatial processes and forms of organization of the productive forces, in order to optimize and improve production efficiency; regionalization, promoting deeper identifying the structure, function, increased understanding of the regions, the study and development of a geographical approach to the management of the region; greening, characteristic of the whole complex of geographical sciences dealing with the interaction of society and nature. Presents the contribution of prominent scientistsgeographers: V.M.Maksakovskogo - his recommendations for the Study of the greening of industry and spatial aspects; YD Demetrius, releasing a comprehensive study of the major issues of geo-ecological problems; A.M.Trofimova, MD Sharygina on the role of general geography - basic science, which considers all aspects of the development of an integrated system of "nature-economy-population" in the space-time aspect, as well as trends in long-term development of geographical education. The contribution of scientists CFI and the Institute of Ecology and Mineral Sciences of the Republic of Tatarstan in the environmental mapping.

Keywords: geographical education, humanitarianism and humanization, sociologization greening, economization, regionalization.

\section{Introduction}

Russia's accession to the Bologna process has contributed to the modernization of education - a focused process of education and training. The process of education is aimed at building knowledge, skills, experience, creativity, intellectual and moral qualities, spiritual values, professional competence, development and cultivation of future specialists.

The modern period of the development of education is characterized by updating the content and structure of the studied disciplines.

Inevitable changes have affected and geographical education. As the priorities of content updates geographical entities to humanization and humanization, aimed at identifying the humanistic spirit and the personal meaning of the studied geographical disciplines, and ultimately the formation of a scientific world outlook and geographical culture.

\section{Method}

When writing articles to apply theoretical and empirical methods: the study and analysis of the methodological, geographical, psychological and educational literature, the study of legal and procedural documentation, teaching experience, observation of the learning process.

\section{The Main Part}

In the scientific and methodical literature along with the general geographic integration of isolated two types of integration: the border and cross-cutting areas. Border integration is largely due to the emergence of the trend towards humanization 
and humanization, including sotsiolizatsiyu, economization and the greening of geographical education.

One of the most important priorities of the Russian Geographical Education is humanization - the introduction of human subject content of education. Humanization of education is a system of measures aimed at the priority development of common cultural components in the content of education, including geographic, and on the formation of personal maturity of the students. It is culture that determines the formation of the person. [1] The most important practical direction of the humanization of geographical education is the revision of curricula and programs for socioeconomic disciplines, to provide substantial assistance to students in understanding the history and the present, world and national cultural heritage [2,3]. At the time, NN Baranskii suggested that "physical geography - is unnatural, and economic - is immoral," referring to the fact that nature is seen as a resource base of the economy, rather than habitat, and human evolution. [4]

In the literature in recent years have begun to talk about the humanization of geographical education. According to the humanization of the content of geographical education should ensure the free and full development of personality, the active participation of the individual in society. [3]

Consequently, the idea of humanization, according to many researchers, also apply to the forms and methods of training, on the totality of conditions in which they occur. In the study of the geography of the learning process should be structured in such a way that the student discovering the personal significance of geographical knowledge and on this basis mastered the content of the physical and economic geography, and other geographic disciplines.

VP Maksakovskii talks about the humanization of geographical education as follows: "... as in all of science, humanization is associated with turning to the man, and all areas of his life and cycles. In fact, it's a whole new world, affirms universal, common cultural heritage and considers primarily the lives of people and their social relations "[5]. An interesting interpretation of the humanization of geography education in his "Fundamentals of geography" gives YG Mashbitz, who believes that "modern geography - is the science of" human "," from the man, "and in many ways" through a man. "At the forefront of her come a bunch of "man - nature", "people - agriculture", "man - the territory", "human environment" [6]. Consequently, at the forefront of the humanization of geographical education goes a man with all his relations to the environment.

The next trend in geographic education - sociologization geographical education. According to VP Maksakovskii, many scientists sociologization is closely related to the humanization of education and is a general trend throughout the science and social practice, "is to raise attention to the social aspects of development" [5]. According to him, the beginning of sociologization national geography and related sciences is at the beginning of 80-ies of XX century and is connected with the development of ethnography and social geography, social ecology, social infrastructure and others. Thus, social geography studies the processes and forms of human life mostly in terms of living conditions, recreation, personal development and reproduction of human life. [7] The object of her research are the various territorial community of people, including all of humanity as a whole, ie sociosphere. In our opinion, sociosphere - a set of geographic and socio-economic factors specific to the stage of development of society in its interaction with nature.

In the development of geographical education hold a special place and economization of questions, especially since the early 90 -ies of XX century, in connection with the transition to a market economy. Economization issues received much attention in the study of economic and social geography of the regional economy, as it examines the spatial processes and forms of organization of the productive forces in order to optimize and improve production efficiency. Therefore, in the scientific literature more intensively started to use these integrated concepts as "economic and geographical space", "economic and geographical area", "economic and geographical field," et al. [8].

Due to Russia's transition to a market economy and the transformation of a general methodological framework, in universities in the study of economic geography began to use terms such as "market economy", "business", "economic resources", "quality of life" and others.

In K (L) FU for third year students enrolled in the specialty 050103 "Geography", offers courses: "Foundations of the market economy", "Regional Economy", "Economic-geographical features of the Republic of Tatarstan".

In the study of economic geography in higher education system plays a vital role regionally and economic knowledge and economization of geographical education. It relies on a system of scientific knowledge on environmental management, the distribution of production and resettlement of the population who are the most important areas of interaction between nature and society.

In a market economy, there is a strengthening of interaction between nature and the economy, between nature and man, the aggravation of ethnic phenomena, which requires the establishment of effective geographical division of labor, the rational use of the economically active population, the effective use of the territory and the nature [9].

Since 70-ies of XX century, more intensive in the greening of geographic education, which involves consideration of the human hand in hand with his environment. Greening is also characteristic for the entire interdisciplinary complex of 
geographical science, which explores the interaction of society, production and the environment. We can say that in recent times there has been some greening of both natural and social sciences, and these processes have led to increased synthesis of science and human knowledge. Especially developing rapidly greening the physical geography of Russia, economic and social geography, biogeography, geography of soils, geography Tatarstan, etc.

In the study of economic and social geography of Russia, in particular the theme "Natural resource factor in the development of Russia", attention is paid to environmental and economic education, the role of natural resources in economic development, changing environmental conditions under the impact of human activity, methods of valuation of natural resources, sustainable and efficient use of natural resources and the environment, geo-ecological research in Russia. In the study of industries, agriculture and transport also need to use additional information and teaching materials geographical and ecological maintenance.

In the study of Russia's regions highlighted issues such as the "environmental factor", "Environmental Protection", "Regions of ecological disaster", "The ecological status of the territory of Russia", "Environmental Management" and others. When studying the economic regions of Russia is considered their brief ecological and economic characteristics and environmental issues, and sustainable use of natural resources in each economic region.

VP Maksakovskii in his writings recommends considering the greening of geography at the sectoral and spatial aspects. In the first scenario, the greening of industry physical and economic - geographical disciplines - climatology, hydrology, soil geography, population geography and others. In the second case, we can talk about the three main levels of the territorial application of greening: a) the global level - consideration of a global environmental problem and global changes in the environment; b) the regional level; c) the local level [5,10].

In the scientific and methodical literature within the geographical entity, a new direction - geo-ecological approach. In the works [11, 12], scientists have determined the content of Geoecology as follows: a) the control of environmental changes, ie anthropogenic monitoring; b) projections of impacts of economic activity on the environment; $c$ ) the prevention, alleviation and elimination of natural disasters; d) optimization environment created by natural and technical systems.

In the monograph of scientists of the Faculty of Geography and Geoecology, St. Petersburg State University discussed in more detail the relationship of geography and ecology, the authors give the following definition of Geoecology "Geoecology-science that studies the irreversible processes and phenomena in the natural environment and the biosphere resulting from intense anthropogenic impact, and also near and distant in time the consequences of these actions "[12].

As can be seen from this definition, this paper questions of geography and ecology are considered integrated. Despite this, the proposed problems geoecology are generally reduced to the problem of the impact of society on nature, and the other side of a single process - the nature of the impact on society - missed. In its work, YD Demetrius highlights the major issues of complex study of geo-environmental problems and their impact: a) on the human body of the surrounding nature; b) on human society of the whole complex of natural conditions; $c$ ) to human society, they altered the natural (ie, technical) environment; g) the effect of nature on the socio-cultural and ethnic environment, and others. [11].

Great development in recent years has received environmental mapping, which includes the creation of maps of human impacts on the environment; risk maps of natural hazards and environmental emergencies; complex

environmental cards; maps of ecological management; environmental cards-natural systems.

Scientists K (R) FS, Institute of Ecology and subsoil of the Academy of Sciences of the Republic of Tatarstan on the basis of ecological mapping prepared and published the following cartographic products:

- Atlas of the Republic of Tatarstan (a section "Natural Resources and the Environment" and thematic maps: 1) human influences, 2) anthropogenic impact, and 3) the intensity of the manifestations of emergencies, 4) environmental map and others.

- Ecological map of the Kuibyshev Reservoir;

- Ecological map of the Republic of Tatarstan, and others.

All of these cartographic materials have been successfully used by teachers of high schools in the educational process as information $\neg$ didakticheskie materials.

In the works of AM Mills, MD Sharygina considered the essence of object-subject unified geography, describes the principles and approaches of geographical science methodology, research methods and techniques, a snapshot of the scientific research in geography, the study of the theory of the organization of geographical space, the geographical field, geosystems, geographical zoning, etc. And identify trends in long-term development of geographical education and its ability to solve problems of territorial development and management [2]. We believe that the geographic entity in recent years, in the course of modernization of Russian education is becoming popular in the solution of modern ecogeographic, economic and geographic, social and other territorial issues. 
An analysis of the literature identified several priorities update the content and structure of geographic education in higher education institutions. This humanization humanization and stimulating introduction to the content of human geography education; emergence of cultural, social, behavioral, religious geography; humanization of the forms and methods, a set of learning environments; maximum realization of the whole person, open to new experiences of perception, capable of informed and responsible choices in various situations; socialization, which is closely related to the content humanitarization geography education, including as an object of study various territorial community of people, ie sociosphere; economization, actualization which is associated with the transition to a market economy; suggesting the formation of the system of regional-economic knowledge of environmental management, the distribution of production and resettlement of the population, human interaction - nature - society; greening, the person in question in close connection with his environment, which is characteristic for the entire interdisciplinary complex of Geographical Sciences in the interaction of society, production and the environment; implementing geo-ecological approach as a new direction in geography; regionalization related to regional studies, regional studies, the regional economy; physical and economic regionalization, regional politics, demographics, etc..

\section{Results}

1. Modern processes of integration, characterized by a tendency to humanization, humanization, and crosscutting areas of geography: sociologization, economization, greening are the basis of updating the content and structure of geography education.

2. Gumanitarizatcija focused on the development of common cultural components of education, the study of the experience of cultural heritage. Humanization is expressed in increasing attention to the human factor, the social aspects of the development of society.

3. The process of training and education through the humanization methods, forms of learning becomes studentsignificant and, therefore, forms of thinking, their own attitudes, beliefs.

4. Geography becomes a science for humans. This contributes to the sociologization aimed at comprehensively study the social aspects of geography, and greening, reflecting the interaction of nature and society, the territorial structure of the economy. Forms of production organization.

5. Greening considered by scientists in the sectoral and spatial aspects. There is a new stage in the development of Environmental Geoscience, namely the impact of geo-environmental problems in the human, the human society on the ethical environment, etc.

6. The most important contribution to the development of ecological education content makes economic mapping, which allows to estimate, predict environmental change under the influence of anthropogenic factors.

7. All updates priorities geographical education directed to the fact that geography becomes fundamental science, geography becomes fundamental science that can solve verbal spatio-temporal problems of natural and social systems.

8. The process of learning geography, becoming a student-significant, forms the scientific professional thinking, dialectical scientific outlook and geographic culture.

\section{Conclusion}

In this way, the search for new philosophical orientation in the current difficult situation in modern society enabled the priorities update the content and structure of geographic education: humanitarization, humanization, sociologization, greening, aimed at the formation and development of personality.

Ekogumanisticheskaya and cultural studies focus geographical content, learning sociosphere, economic geography matters in connection with the transition to a market economy, contribute to the formation of emotional and value relationship to reality. Generate values of a personal nature, which would be identical to a human, social - is the task of education. Personal values become when students realize that knowledge and skills, the experience of creative activity - these are the values necessary for further development, they are personally meaningful, therefore, students are attached to the spiritual and material culture of the surrounding society, develop intellectual creativity, formed worldview. 


\section{References}

Mangam I. Relation ships / at work: A matter of Tension and Toler- ance // Personal Relationships / Edit by S. uck and R. Gil-mour / London, 1981.Vol.Studyng Personal Relationships. P. 197-214.

Trofimov 3 AM, Gysin IT, Rubtsov, VA Actual problems of socio-economic geography: Textbook.- Kazan: RIP "School", 2008-176s.

Baranskii NN Economic Geography. Economic mapping / NN Baranskii. - Moscow: Gos. publ "Geographical Literature", 1956 - 306.

Kramin, M. V., Safiullin, L. N., Kramin, T. V., \& Timiryasova, A. V. (2014). Drivers of economic growth and investment attractiveness of Russian regions. Life Science Journal, 11(6s).

Kramin, T. V., Ismagilova, G. N., \& Kramin, M. V. (2014). Assessment of Effect of Large Investment Projects on Development of Investment Potential of Regions of Russia as Exemplified by Universiade 2013 in Kazan1. Mediterranean Journal of Social Sciences, 5(18), 255.

Mashbitz YG Basics of geography / JG Mashbitz. - M .: Education, 1998.-110c.

Basics of Geoecology / Ed. VG Morachevsky. - St. Petersburg, 1994 - 240

Anand S. The concern for equity in health. Journal of Epidemiology and Community Health, 2002, 56: 485-487.

Alaev EB Economic and geographic terminology / EB Alaev. -Ml "Thought", 1977 - 199 p.

Holmes T., Stevens J. Geographic Concentration and Establishment Scale // Review of Economics and Statistics. 84 in 2002.

Maksakovskii VP Geographic culture / VP Maksakovskii. - Jr. humanity. ed. Center VLADOS, 1998.- 416 p.

Demetrius YD Geography and Environment: current status and future / YD Demetrius // Geography at the threshold of the third millennium: Sb. scientific. Tr. By W Congress St Petersburg RGO.-., 1995 S.73-81

Pedagogy: A modern encyclopedia / Comp. ES Rapatsevich. - MNL "tell lies, the word" 2005 - 720c.

Kramin, T. V., Safiullin, L. N., \& Timiryasova, A. V. (2014). Defining Priorities of Management of Investment Attractiveness of the Region and their Consideration in the Framework of Implementing Large Sports Events1. Mediterranean Journal of Social Sciences, 5(18), 275. 